\title{
Peripheral T cell lymphoma, NOS with aberrant $\alpha \beta$ and $\gamma \delta$ T cell receptor expression in a post-heart transplant patient
}

\author{
Shujuan Liu ${ }^{1} \cdot$ April Ewton $^{1} \cdot$ Tara N. Miller $^{1} \cdot$ Arthur W. Zieske $^{1} \cdot$ Michael J. Thrall ${ }^{1} \cdot$ Randall J. Olsen $^{1} \cdot$ Youli Zu $^{1}$. \\ Suyang Hao ${ }^{1}$
}

Received: 16 October 2019 / Accepted: 3 March 2020 / Published online: 2 April 2020

(C) Springer-Verlag GmbH Germany, part of Springer Nature 2020

\begin{abstract}
Three main patterns of T cell receptor (TCR) expression are identified in peripheral T cell lymphoma (PTCL): TCR- $\alpha \beta$ type, TCR $-\gamma \delta$ type, and TCR silent type. Cases of PTCL that express both $\alpha \beta$ and $\gamma \delta$ receptors are rare. Here, we report a case of PTCL-NOS (not otherwise specified) with dual $\alpha \beta$ and $\gamma \delta$ expression in a 61-year-old female 6 years after orthotopic cardiac transplant. The patient presented with fatigue, fever, worsening anemia, and thrombocytopenia. A chest CT showed multiple irregular lung nodules and diffuse lymphadenopathy. Cytology evaluation of the lymph nodes revealed large atypical lymphocytes with immunopositivity for CD3, CD8, CD56, TIA1, and granzyme B and immunonegativity for CD5 and CD30. EpsteinBarr virus (EBV) was not detected by EBV-encoded RNA (EBER) in situ hybridization study. The corresponding flow cytometry demonstrated abnormal T cells with TCR- $\alpha \beta$ and TCR- $\gamma \delta$ expression and loss of CD5 expression. A TCR gene rearrangement study demonstrated the presence of a clonal lymphoid population with TCR $\beta$ and TCR $\gamma$ rearrangements. The patient was deceased within 2 months despite aggressive treatment. The findings were consistent with an EBV-negative, monomorphic $\mathrm{T}$ cell post-transplant lymphoproliferative disorder (PTLD) with features of PTCL-NOS. A literature review of T cell lymphoma with co-expression of TCR- $\alpha \beta$ and TCR- $\gamma \delta$ was performed. A case of aggressive PTCL with dual expression of TCR- $\alpha \beta$ and TCR- $\gamma \delta$ in a post-transplant setting has not been previously reported.
\end{abstract}

Keywords T cell lymphoma $\cdot$ T cell receptor $\cdot$ Post-transplant lymphoproliferative disorder $\cdot$ EBV

\section{Introduction}

T cells develop in the thymus and are defined by their expression of either $\alpha \beta$ or $\gamma \delta$ T cell receptors (TCR), which are composed of different sets of somatically rearranged polypeptide heterodimers. Alpha-beta T cells constitute $95 \%$ of all T cells, while $\gamma \delta \mathrm{T}$ cells comprise $<5 \%$ of all circulating lymphocytes. The majority of T cells in lymphoid tissues are $\alpha \beta$ T cells [1].

Peripheral T cell lymphoma (PTCL) is a heterogeneous group of mature $\mathrm{T}$ cell neoplasms that represents less than $15 \%$ of all non-Hodgkin's lymphoma in adults [2]. Three main patterns of TCR expression can be identified in PTCLs using monoclonal antibodies specific for the $\beta$ chain (beta F1)

Suyang Hao

shao@houstonmethodist.org

1 Department of Pathology and Genomic Medicine, Houston Methodist Hospital, Houston, TX, USA of the $\alpha \beta$-TCR and the $\delta$ chain (anti-TCR delta-1) of the $\gamma \delta$ TCR: the common TCR- $\alpha \beta$ type, the less common TCR- $\gamma \delta$ type, and the TCR silent type [3]. Recently, another rare pattern has been reported in the literature that demonstrates coexpression of both TCR- $\beta$ and TCR- $\gamma$ chains. These include rare variable types of cutaneous $\mathrm{T}$ cell lymphoma (CTCL) [4-8], enteropathy-associated T cell lymphoma (EATL) [9], and extranodal NK/T cell lymphoma (ENKTL), nasal type [10]. However, PTCL-NOS with dual expression of TCR- $\alpha \beta$ and TCR- $\gamma \delta$ in a heart transplant recipient has not been previously reported.

\section{Clinical history}

A 61-year-old female had a past medical history significant for systemic AL amyloidosis which resulted in chronic kidney disease and chronic heart failure. She underwent orthotropic cardiac transplant (OCT) for heart failure 6 years prior to admission and autologous stem cell transplantation 1 year later. Pre-transplant work-up revealed remote EBV infection, 
mismatched CMV status (donor antibody positive, recipient antibody negative), and negativity for HIV, herpes simplex virus (HSV)-1, HSV-2, and human T-cell lymphotropic virus-I/II infections.

Post-transplant immunosuppressive therapy included mycophenolate mofetil, tacrolimus, and prednisone. During the post-transplant phase, the patient received prophylactic and periodic antiviral treatment due to $\mathrm{CMV}$ infection and occasional low CMV viremia (CMV antigen was initially detected in peripheral blood 2 years postOCT by immunofluorescence assay and then multiple times by polymerase chain reaction (PCR), but viral load was consistently $<300 \mathrm{IU} / \mathrm{ml}$, except on one occasion, when it was 1503 IU/ML). An interval cardiac biopsy did not reveal evidence of significant acute rejection. However, amyloid deposit was detected by Congo red stain in the endomyocardial biopsy 2 years post-OCT. The patient received chemotherapy followed by daratumumab due to relapsed disease and subsequently sustained normal kappa/lambda ratio, and serum protein electrophoresis was negative for monoclonal bands. At baseline, she had thrombocytopenia and a chronic normocytic, normochromic anemia 2 years post-OCT. The patient was placed on the renal transplant list 4 years post-OCT due to chronic kidney disease.

The patient presented with fatigue, worsening anemia, thrombocytopenia, and fever 6 years after OCT. CT imaging showed multiple new irregular lung nodules and mass-like consolidations. The differential diagnosis included multifocal pneumonia versus malignancy. Bronchial lavage cultures grew Klebsiella and Candida.
Although broad antibiotics were given, her symptoms did not improve. A subsequent PET CT showed numerous bilateral enlarged mediastinal and hilar lymph nodes with marked uptake $(S U V=15.5)$, innumerable bilateral pulmonary nodular opacities of varying size and density with abnormal uptake $(S U V=14.5)$, and a moderate right pleural effusion (Fig. 1).

Endobronchial ultrasound (EBUS)-guided fine needle aspiration (FNA) and biopsy of the hilar and mediastinal lymph nodes were performed to evaluate the lesion. A final diagnosis of PTCL-NOS with features consistent with an EBV negative, monomorphous T cell PTLD was made.

The patient received dexamethasone, vincristine, adriamycin, and cyclophosphamide for lymphoma, piperacillin and tazobactam injection for Klebsiella pneumonia, and valacyclovir for infection prophylaxis. Tacrolimus was reduced, and mycophenolate mofetil was discontinued. The patient's lymphoma was resistant to chemotherapy, and she developed a malignant pleural effusion with acute respiratory and renal failure. The patient died within 2 months of the lymphoma diagnosis.

\section{Materials and methods}

\section{Morphologic studies and immunohistochemistry}

Papanicolaou and Diff-Quik stains were performed on the smears from FNA specimens from the lymph nodes. Cell blocks were prepared according to standard protocols.
Fig. 1 PET CT demonstrates widespread hypermetabolic disease involving the chest, retroperitoneum, and mesentery/ omentum and a moderate pleural effusion
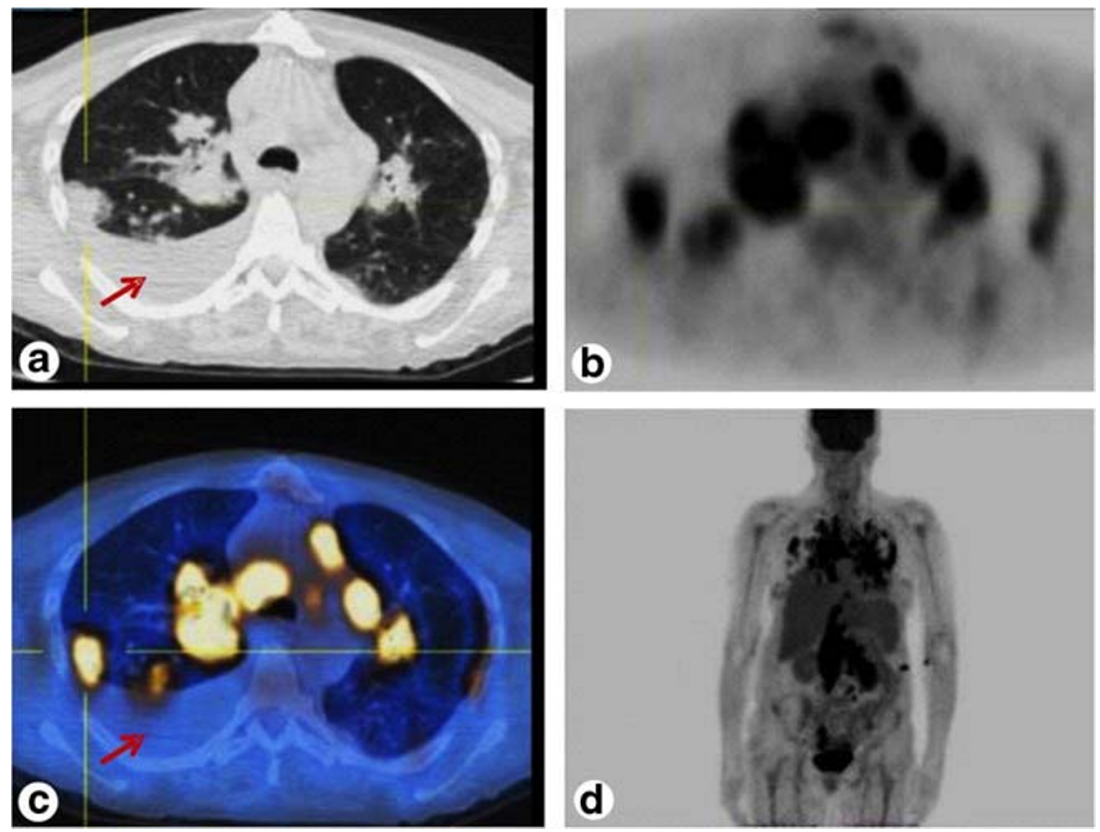
Sections of the cell blocks were stained with hematoxylin and eosin (H\&E).

An immunohistochemical panel was performed on the cell block using standard protocols. The following antibodies were used: CD3, CD4, CD5, CD8, CD20, CD30, CD56, TIA1, and granzyme B. In addition, an EBV stain for EBER by chromogenic in situ hybridization (ISH) was also performed.

\section{Flow cytometry}

Multiple-color flow cytometry was performed on the lymph node FNA on a FACSCanto cytometer using FACSDiva software (Becton-Dickinson, San Jose, CA). Primary lymphocyte gating utilized CD45 and side light scatter (SSC) of the CD45 bright/SSC low population. The following antibody panels were used: CD2, CD3, CD4, CD5, CD7, CD8, CD19, CD20, CD45, CD56, CD57, CD45 RA, TCR- $\alpha \beta$, and TCR- $\gamma \delta$ (Becton-Dickinson, San Jose, CA). Antigen expression was interpreted as negative, dim, or positive, as compared to the intensity of the corresponding normal cell type.

\section{T cell receptor gene rearrangements by polymerase chain reaction (PCR)}

DNA was extracted from unstained sections of the cell block from the lymph node according to standard protocols. Genomic DNA was amplified by PCR using primers targeting the conserved framework (FR) and joining (J) regions as well as the diversity (D) and joining $(\mathrm{J})$ regions of the TCR beta $(\mathrm{TCR} \beta)$ gene and primers targeting the conserved regions within the variable $(\mathrm{V})$ and joining $(\mathrm{J})$ regions of the TCR gamma (TCR $\gamma$ ) gene. PCR products were then analyzed by differential fluorescence detection using capillary electrophoresis. All reactions were performed in duplicate.

\section{Results}

FNA of the hilar and mediastinal lymph nodes revealed scattered and aggregates of large atypical neoplastic cells with round or irregular nuclei with hyperchromatic chromatin in a background of necrosis (Fig. 2A). Immunohistochemical
Fig. 2 Fine needle aspiration biopsy of the hilar and mediastinal lymph nodes revealed lymphoma cells. A. Cell block (a H\&E stain $\times 200$, b H\&E stain $\times$ $600)$ and FNA smears (c PAP stain and d Diff Quik stain, $\times$ 1000) revealed large-sized atypical lymphocytes with round or irregular nucleus with hyperchromatic chromatin. B. The lymphoma cells are positive for CD3, CD8, TIA1, and granzyme $\mathrm{B}(\mathrm{GrB})$, and negative for $\mathrm{CD} 5(\times 200)$. $\mathrm{EBV}$ is negative by EBER in situ hybridization study $(\times 200)$
A

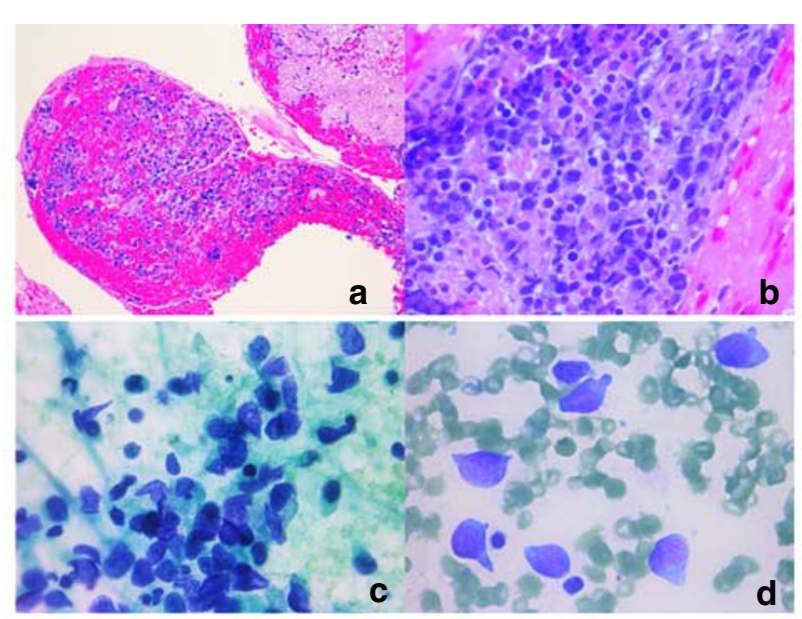

B

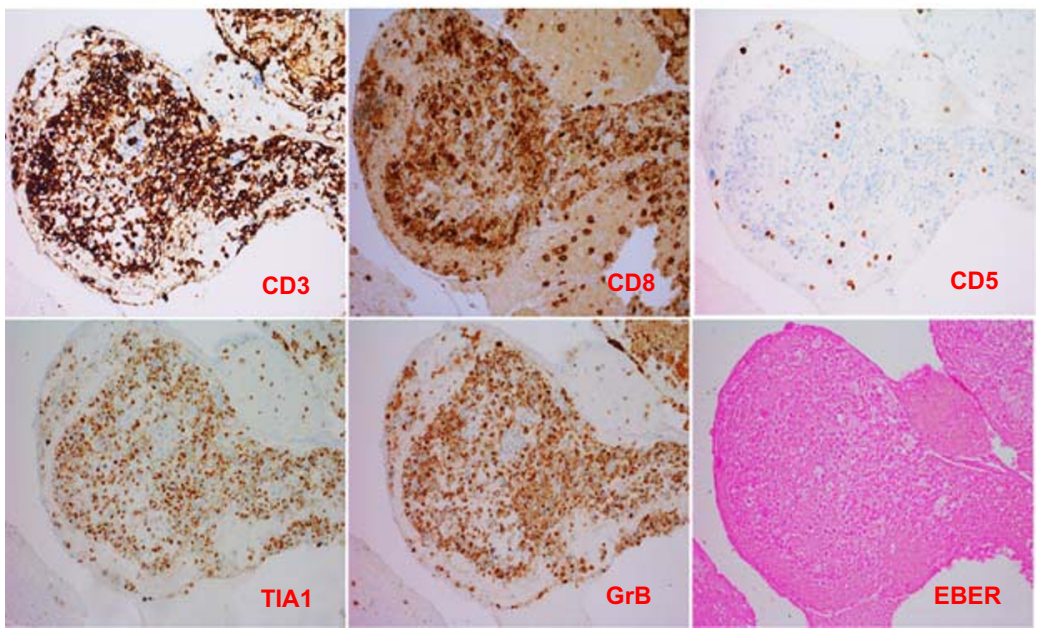



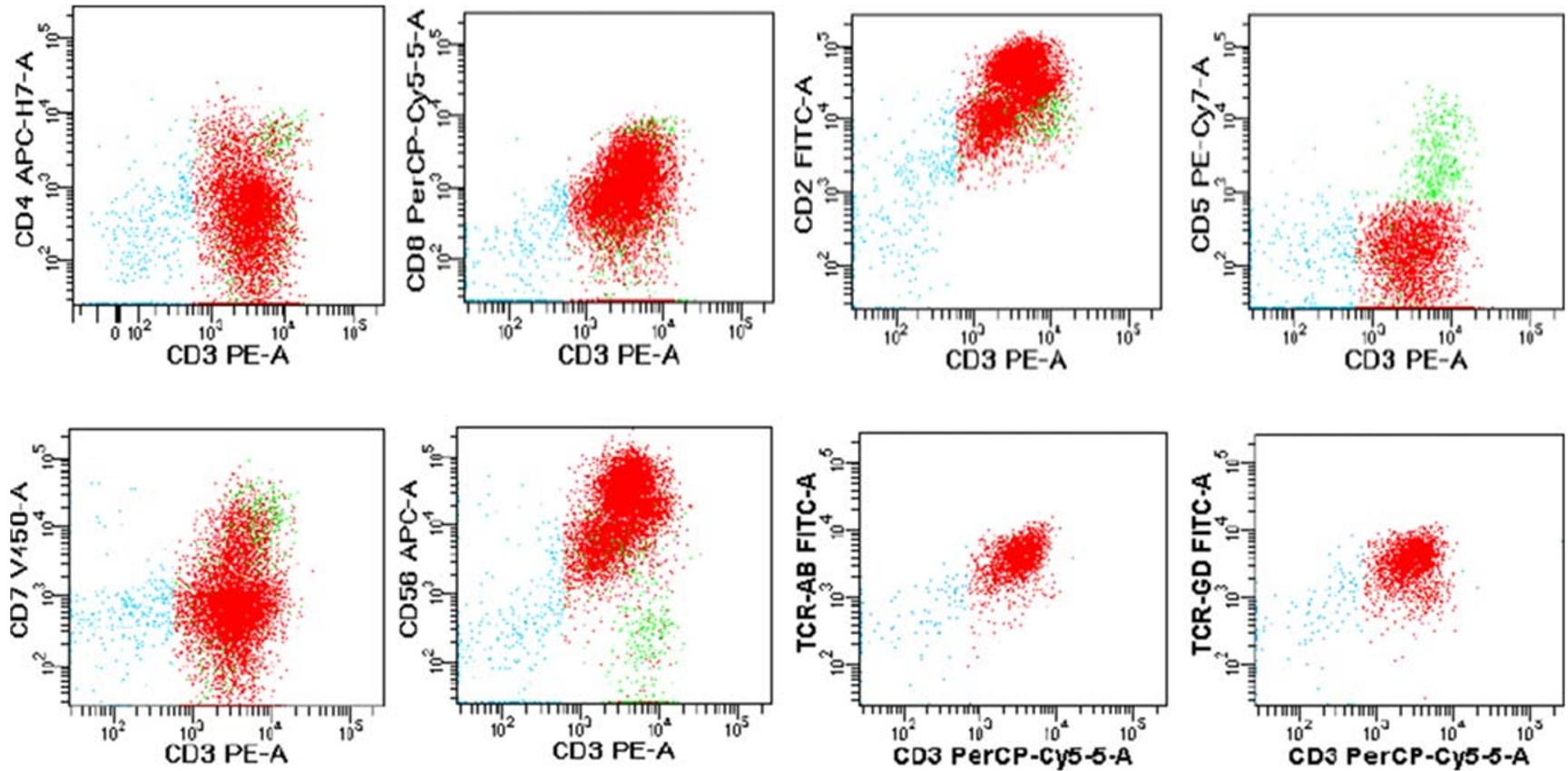

Fig. 3 Flow cytometry study revealed atypical T lymphocytes (Red population, gated on CD45+ lymphocytes). Positive: CD3, CD2, CD8 (dim), CD56, TCR- $\alpha \beta$, and TCR- $\gamma \delta$. Negative: CD4, CD5, CD7

studies showed the neoplastic cells to be positive for CD3, CD8, CD56 (not shown), TIA1, and granzyme B and negative for CD4 (not shown), CD5, and CD30 (not shown). EBV was negative by EBER in situ hybridization study (Fig. 2B).
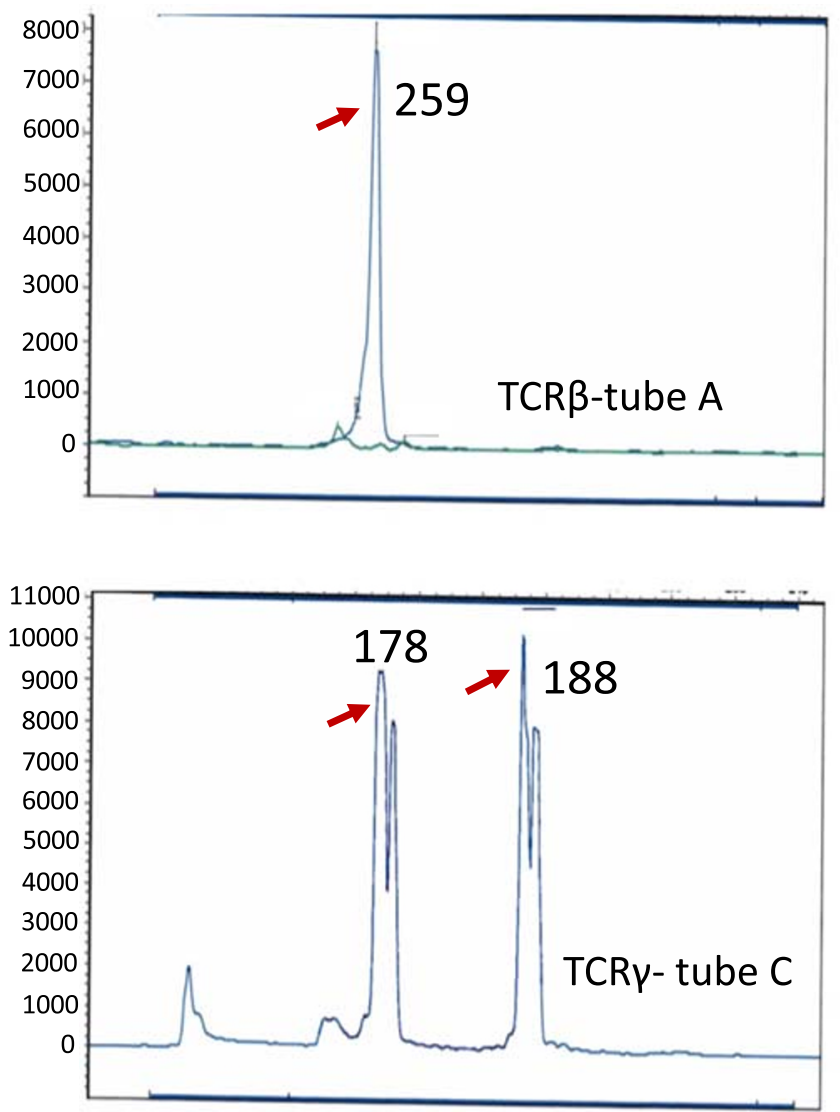

The corresponding flow cytometry study demonstrated an atypical $\mathrm{T}$ cell population with an immunophenotype positive for CD2, CD3, CD8 (dim), CD45, CD56, TCR- $\alpha \beta$, and TCR- $\gamma \delta$ and negative for CD4, CD5, and CD7 (Fig. 3).

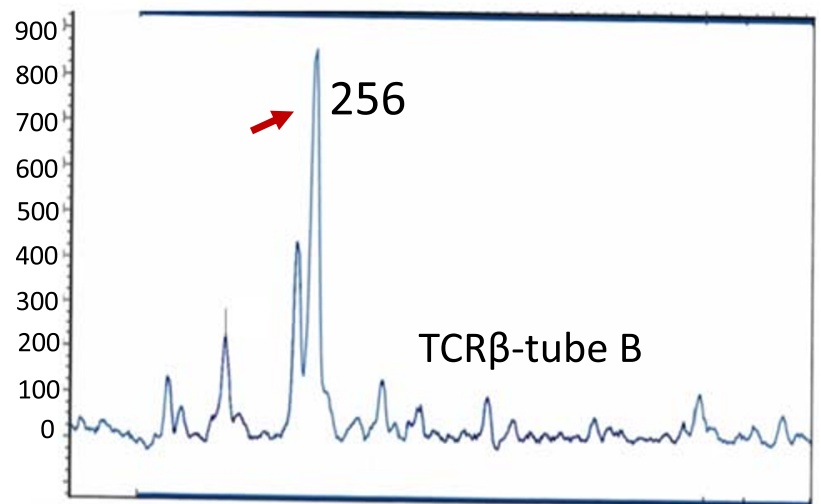

Fig. 4 The TCR gene rearrangement studies revealed the presence of a clonal lymphoid population with TCR $\beta$ and TCR $\gamma$ rearrangements 


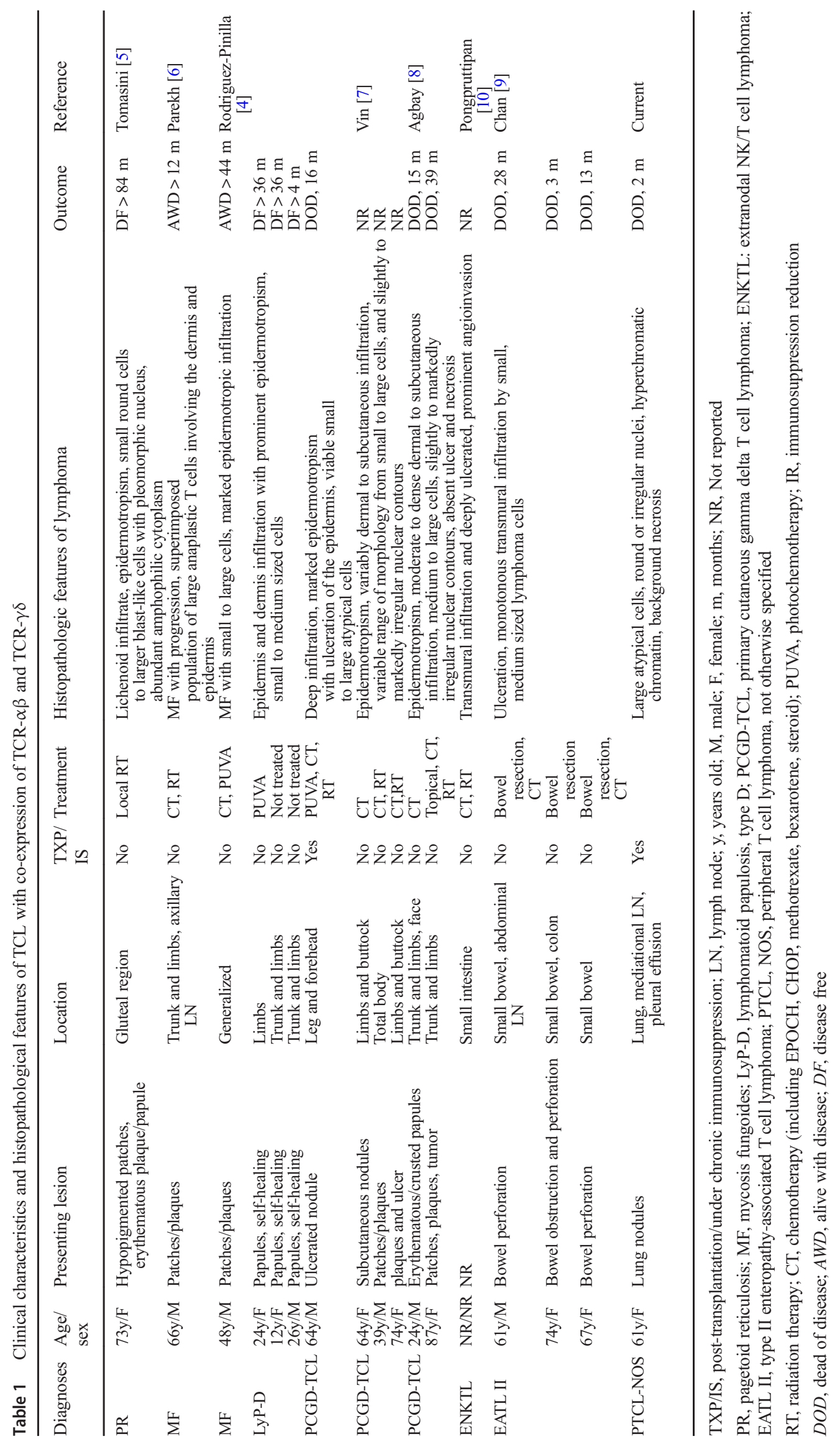


The lymphoma cells were also positive for $\mathrm{CD} 26, \mathrm{CD} 38$, and CD45RO and negative for CD25, CD57, and CD45RA and B cell markers (not shown). The TCR gene rearrangement studies revealed the presence of a clonal lymphoid population with TCR $\beta$ and TCR $\gamma$ gene rearrangements (Fig. 4).

The histopathological, immunophenotypic, and molecular findings were consistent with PTCL-NOS. Given the patient's history of cardiac transplantation, the findings may represent an EBV-negative, monomorphic T-cell PTLD with features of PTCL-NOS. A peripheral blood and bone marrow evaluation was performed and did not reveal involvement by $\mathrm{T}$ cell lymphoma.

\section{Discussion}

This patient's PTCL has an unusual immunophenotype: dual expression of TCR- $\alpha \beta$ and TCR- $\gamma \delta$, detected by flow cytometry study and immunohistochemistry and confirmed by T cell gene arrangement PCR study. Lymphomas with coexpression of TCR- $\alpha \beta$ and TCR- $\gamma \delta$ are rare. A small number of cases have been reported, including CTCL [4-8], type II EATL involving the small bowel or colon [9], and ENKTL, nasal type [10], involving the small bowel. The clinical characteristics and histopathological features of reported TCL with co-expression of TCR- $\alpha \beta$ and TCR- $\gamma \delta$ are listed in Table 1. The patients included nine women, seven men, and one individual of unreported sex, with ages ranging from 12 to 87 years (mean, 54 years; median, 62.5 years). Twelve out of 17 cases $(71 \%)$ were CTCLs, while four other cases (ENKTL, EATL II) demonstrated intestinal involvement (24\%). The histopathological features were variable. All the CTCL cases demonstrated epidermotropism with variable infiltration patterns ranging from superficial dermal to deep subcutaneous involvement. Most CTCL cases did not show ulceration and necrosis; however, the cases with intestinal involvement demonstrated transmural infiltration and ulceration. The patients with PCGD-TCLs or other non-CTCLs showed worse prognosis despite systemic therapy (chemotherapy and/or radiation). The lymphoma in the current case occurred in a post-transplant, immunosuppressive patient, demonstrating lung and lymph node involvement with associated tumor necrosis and resultant demise.

All reported lymphoma cases with dual TCR- $\alpha \beta$ and TCR $-\gamma \delta$ expression exhibited a cytotoxic phenotype (Table 2). In addition, CTCLs showed frequent expression of CD30 and were negative for EBV by EBER-ISH study. Cases of type II EATL showed both negative CD30 expression and EBV, and the case of ENKTL, nasal type, showed both positive expression of CD30 and EBV EBER. Besides the unusual co-expression of TCR- $\alpha \beta$ and TCR- $\gamma \delta$, the current case demonstrated a cytotoxic $\mathrm{T}$ cell immunophenotype consistent with the findings in all the reported cases. In

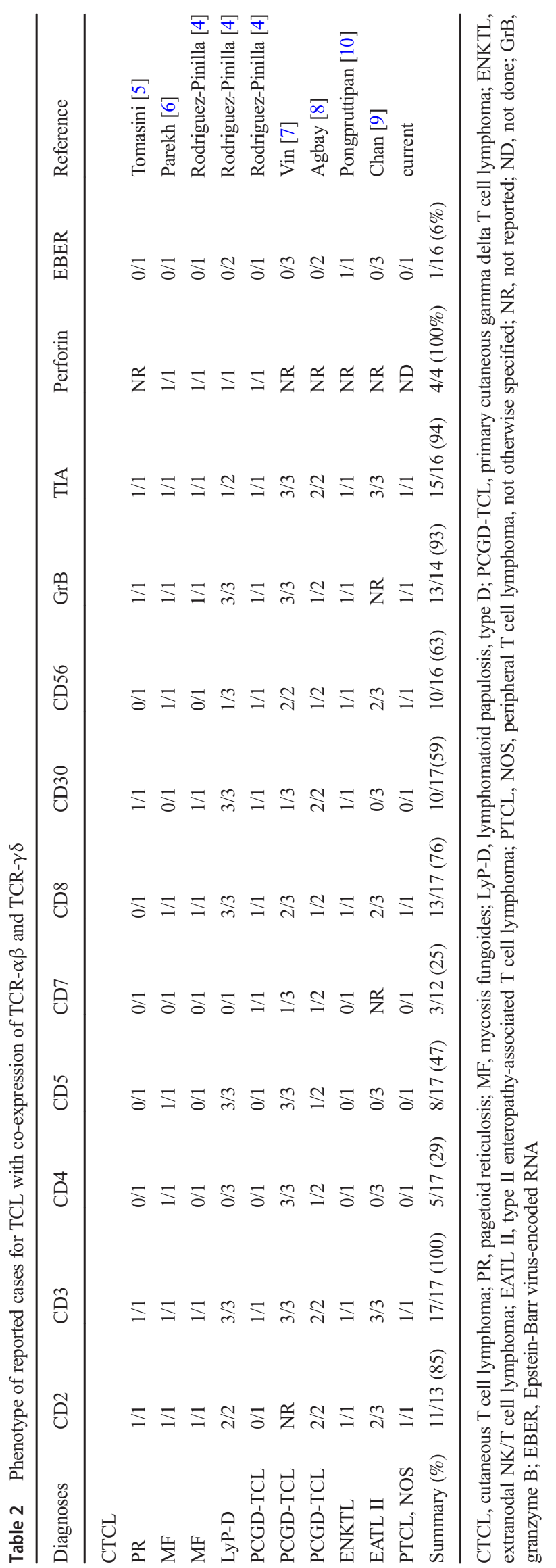


addition, the negative CD30 and EBER-ISH expression pattern in the current case was similar to that of the majority of the reported cases of type II EATLs.

The PTCL-NOS in the current case developed in a posttransplantation setting, which raises the possibility of a $\mathrm{T}$ cell PTLD. Among all the reported cases, there was only one other case [4] in which a status post-liver transplantation patient who was under chronic immunosuppression developed PCGD-TCL. T/NK-cell PTLD is uncommon and accounts for $15 \%$ of all PTLDs. They include almost the entire spectrum of T and NK-cell neoplasms with the largest group being PTCL-NOS. Studies [11] showed the T/NK-cell PTLDs occur at a median of 66 months posttransplantation and usually occur at an extranodal site. In contrast to B cell PTLDs, most of which are associated with EBV infection, only about one third of T/NK-cell PTLDs are EBV positive. The EBV-negative T/NK-cell PTLDs have a median survival of 6 months, which is significantly shorter than EBV-positive T/NK-cell PTLDs [11]. In contrast, the non-post-transplant PTCL-NOS has a longer survival than both EBV-positive and EBVnegative T/NK-cell PTLDs [12]. Our case developed 6 years post-transplantation. The lymphoma involved extranodal sites and was EBV negative. The patient died within 2 months of the lymphoma diagnosis, despite aggressive treatment. The overall features were consistent with an EBV-negative, T cell PTLD with a rare immunophenotype with co-expression of TCR- $\alpha \beta$ and $\mathrm{TCR}-\gamma \delta$. In comparison with our case, the other reported case [4] that developed after transplantation was PCGDTCL, which involved the skin of leg and forehead and was also EBV negative. The patient was treated with chemoand radiation therapy and deceased 16 months after diagnosis.

Both $\alpha \beta$ and $\gamma \delta$ T cells develop from CD4/CD8 doublenegative thymocytes. TCR $\gamma$ and $\delta$ rearrangement occurs prior to TCR $\beta$ recombination in $\gamma \delta$ precursor cells. The expression of $\gamma \delta$-TCR and CD3 complex on the cell membrane initiates intracellular signaling pathways to generate functional TCR $-\gamma \delta$ chains. The commitment to the $\alpha \beta$ T cell lineage is induced by pre-TCR complex, which is made up of a rearranged TCR $\beta$ chain with the invariant $\mathrm{pT} \alpha$ and $\mathrm{CD} 3$ subunits, followed by rearrangement of the TCR $\alpha$ gene to form the complete $\alpha \beta$-TCR/CD3 complex [13]. TCR $\alpha$ gene rearrangement results in the excision of TCR $\delta$ gene; TCR- $\alpha \beta$ and TCR $-\gamma \delta$ expression have previously been thought to be mutually exclusive $[1,14]$. This concept may partially be attributed to the rarity of reported cases with co-expression of TCR $-\alpha \beta$ and TCR- $\gamma \delta$, as most T cell lymphoma cases are not tested for both TCR- $\alpha \beta$ and TCR- $\gamma \delta$ expression. The dual expression of TCR- $\alpha \beta$ and TCR- $\gamma \delta$ in the current case was detected by flow cytometry study. The wide utilization of flow cytometry, as well as the relatively recent availability of immunohistochemistry for TCR- $\alpha \beta$ and TCR- $\gamma \delta$ in the diagnosis of lymphoid neoplasms, may increase the frequency of detection of this phenotype.

The dual TCR expression may represent a phenotypic aberration due to genetic instability. Agbay and coauthors studied immunophenotypic shifts in PCGD-TCL by comparing the immunophenotypic profiles in sequential biopsies from nine patients [8]. Two cases in this study showed coexpression of $\alpha \beta$ - and $\gamma \delta$-TCR. Interestingly, one case showed decreased $\beta$ expression in the following biopsy, while another case showed double expression in the sequential biopsy following an initial isolated $\gamma \delta$ expression. The authors proposed that immunophenotypic shifts may result from environmental factors or an accumulation of mutations that induce a different antigenic profile. In favor of this hypothesis, a recent study reported that lineage plasticity can occur in a subtype of $\gamma \delta \mathrm{T}$ cells, which may develop into $\alpha \beta$ T cells under inflammatory conditions [15].

Although the case reported here developed in a posttransplantation setting, EBV did not appear to play a key role in the pathogenesis of this case. However, serial CMV DNA viral load studies revealed chronic, albeit low level, CMV infection. Chronic antigenic stimulation, from CMV, or other environmental factors such as cytotoxic therapies or immunosuppressive agents may have played a role in the development of this unusual PTCL.

In summary, we report a rare case of aggressive PTCLNOS with dual expression of $\alpha \beta$ - and $\gamma \delta$-TCR in an EBVnegative post-transplant setting with features consistent with a T cell PTLD.

\section{Compliance with ethical standards}

Conflict of interest The authors declare that they have no conflict of interest.

\section{References}

1. Ciofani M, Zuniga-Pflucker JC (2010) Determining gammadelta versus alphass T cell development. Nat Rev Immunol 10:657-663

2. Swerdlow SH, Campo E, Pileri SA, Harris NL, Stein H, Siebert R, Advani R, Ghielmini M, Salles GA, Zelenetz AD, Jaffe ES (2016) The 2016 revision of the World Health Organization classification of lymphoid neoplasms. Blood 127:2375-2390

3. Gaulard P, Bourquelot P, Kanavaros P, Haioun C, Le Couedic JP, Divine M, Goossens M, Zafrani ES, Farcet JP, Reyes F (1990) Expression of the alpha/beta and gamma/delta T-cell receptors in 57 cases of peripheral T-cell lymphomas. Identification of a subset of gamma/delta T-cell lymphomas. Am J Pathol 137:617-628

4. Rodriguez-Pinilla SM, Ortiz-Romero PL, Monsalvez V, Tomas IE, Almagro M, Sevilla A, Camacho G, Longo MI, Pulpillo A, DiazPerez JA, Montes-Moreno S, Castro Y, Echevarria B, Trebol I, Gonzalez C, Sanchez L, Otin AP, Requena L, Rodriguez-Peralto JL, Cerroni L, Piris MA (2013) TCR-gamma expression in primary cutaneous T-cell lymphomas. Am J Surg Pathol 37:375-384 
5. Tomasini D, Niccoli A, Crivelli F (2015) Pagetoid reticulosis tumor cells with double expression of TCRgammadelta and TCRalphabeta: an off-target phenomenon or genuine expression? J Cutan Pathol 42:427-434

6. Parekh V, Shim EH, Knapp CF 3rd, Hughey L, Elmets CA, McKay K (2016) Primary cutaneous T-cell lymphoma with Coexpression of T-cell receptors alphabeta and gammadelta. Am J Dermatopathol 38:66-72

7. Vin H, Talpur R, Tetzlaff MT, Duvic M (2014) T-cell receptorgamma in gamma-delta phenotype cutaneous T-cell lymphoma can be accompanied by atypical expression of CD30, CD4, or TCRbetaF1 and an indolent clinical course. Clin Lymphoma Myeloma Leuk 14:e195-e200

8. Agbay RL, Torres-Cabala CA, Patel KP, Merril ED, Duvic M, Quesada A, Prieto VG, Aung PP, Loghavi S, Young KH, Hu S, Ferrufino-Schmidt MC, Tetzlaff M, Li S, Medeiros LJ, Miranda RN (2017) Immunophenotypic shifts in primary cutaneous gammadelta T-cell lymphoma suggest antigenic modulation: a study of sequential biopsy specimens. Am J Surg Pathol 41:431-445

9. Chan JK, Chan AC, Cheuk W, Wan SK, Lee WK, Lui YH, Chan WK (2011) Type II enteropathy-associated T-cell lymphoma: a distinct aggressive lymphoma with frequent gammadelta T-cell receptor expression. Am J Surg Pathol 35:1557-1569

10. Pongpruttipan T, Sukpanichnant S, Assanasen T, Wannakrairot P, Boonsakan P, Kanoksil W, Kayasut K, Mitarnun W, Khuhapinant A, Bunworasate U, Puavilai T, Bedavanija A, Garcia-Herrera A, Campo E, Cook JR, Choi J, Swerdlow SH (2012) Extranodal
NK/T-cell lymphoma, nasal type, includes cases of natural killer cell and alphabeta, gammadelta, and alphabeta/gammadelta T-cell origin: a comprehensive clinicopathologic and phenotypic study. Am J Surg Pathol 36:481-499

11. Swerdlow SH (2007) T-cell and NK-cell posttransplantation lymphoproliferative disorders. Am J Clin Pathol 127:887-895

12. Federico M, Bellei M, Marcheselli L, Schwartz M, Manni M, Tarantino V, Pileri S, Ko YH, Cabrera ME, Horwitz S, Kim WS, Shustov A, Foss FM, Nagler A, Carson K, Pinter-Brown LC, Montoto S, Spina M, Feldman TA, Lechowicz MJ, Smith SM, Lansigan F, Gabus R, Vose JM, Advani RH, Network TcP: Peripheral T cell lymphoma, not otherwise specified (PTCLNOS) (2018) A new prognostic model developed by the International T cell Project Network. Br J Haematol 181:760-769

13. Muro R, Takayanagi H, Nitta T (2019) T cell receptor signaling for gammadeltaT cell development. Inflamm Regen 39:6

14. de Villartay JP, Hockett RD, Coran D, Korsmeyer SJ, Cohen DI (1988) Deletion of the human T-cell receptor delta-gene by a sitespecific recombination. Nature 335:170-174

15. Ziegler H, Welker C, Sterk M, Haarer J, Rammensee HG, Handgretinger R, Schilbach K (2014) Human peripheral CD4(+) Vdelta1(+) gammadeltaT cells can develop into alphabetaT cells. Front Immunol 5:645

Publisher's note Springer Nature remains neutral with regard to jurisdictional claims in published maps and institutional affiliations. 